\title{
The Relationship Between Unemployment and Economic Growth in South Africa: VAR Analysis
}

\author{
Waqar Khalid ${ }^{1}$, Ergin Akalpler ${ }^{2}$, Sheheryar Khan ${ }^{3}$, \\ Naveed Hussain Shah ${ }^{4}$ and Sheheryar Khan ${ }^{5}$
}

\begin{abstract}
This article aims to study real GDP, inflation rate, exchange rate and their impacts on the unemployment rate in South Africa by considering the annual time-series data covering the period 1980-2018. The findings of the Johansen approach to cointegration concluded that there was no evidence of a long-run connection among the variables. The findings of Granger causality reported that there was bidirectional causality between the pairs of real GDP vs. unemployment rate, exchange rate vs. unemployment rate, and inflation rate vs. unemployment rate; however, a unidirectional causality was found in the pairs of real GDP vs. exchange rate and inflation rate vs. exchange rate. The findings of impulseresponses demonstrated that there was a negative significant response of the exchange rate to the unemployment rate in the long-run; conversely, the response of real GDP to the unemployment rate was positive significant in the long-run. Furthermore, the findings of variance decompositions reported that all regressors strongly predict the unemployment rate both in the short and long-run. The study suggested that the government should provide job-readiness skills, business awareness, technological knowledge, and training programs to its population to ascertain unemployment reduction. The study also suggested that the South African government should create a supportive environment and flexible labor market policies that attract small businesses and private-sector investment which ultimately strengthen the entrepreneurial activity with new entrepreneurial actors in order to create job opportunities and absorb a large pool of unemployed youth.
\end{abstract}

Keywords: Unemployment, Economic Growth, Inflation Rate, Exchange Rate, VAR Analysis, South Africa

JEL Classification: C5, C51, E24, E31, O11, O55

\footnotetext{
${ }^{1}$ PhD Scholar, Department of Economics, Near East University, Nicosia/TRNC, Northern Cyprus.

${ }^{2}$ Assistant Professor, Department of Economics, Near East University, Nicosia/TRNC, Northern Cyprus.

${ }^{3}$ Department of Business Studies, Pakistan Institute of Development Economics (PIDE), Islamabad, Pakistan.

${ }^{4}$ Assistant Professor, Department of Management Sciences, University of Swabi, Khyber Pakhtunkhwa, Pakistan.

${ }^{5}$ Department of Business Studies, Pakistan Institute of Development Economics (PIDE), Islamabad, Pakistan.

Corresponding author's Email: waqarkhalidicp@gmail.com
} 


\section{Introduction}

Unemployment is considered the major macroeconomic issue of the developing countries and the economy of South Africa is one of them (Bakhshi and Ebrahimi, 2016). Inflation, real GDP, and unemployment in economies are considered the three essential determinants of economic development. The major goal of an economy, whether it is developed or developing, is to achieve price stability, unemployment reduction, and sustained economic growth over a longer period of time through the formulation and application of prudent macroeconomic policies (Tanha, 2018). Moreover, the exchange rate is another important macroeconomic indicator for measuring the economic performance of an economy (Islam and Sahajalal, 2019). South Africa's total income almost increased threefold to peak at 400 billion dollars in the fiscal year 2011 but has recently decreased to around 385 billion dollars in 2019, thus resulted in a slow rise in the growth rate of South Africa of about 1.5\% in 2019 (MTBPS, 2018). The rationale behind this poor performance of the South African economy is the slow expansion in production volume by industries and the provision of inadequate employment opportunities to the general public by the government. As per the schedule of MTBPS (2018), the GDP growth rate is forecasted to reach $2.1 \%$ by 2021 , and this target can be achieved by effective government spending on infrastructural development, ensuring price stability, and youth employment generation.

The reported macroeconomic variables are significantly interlinked and interconnected with each other either in a direct or an indirect way. For instance, the high inflation rate depreciates the domestic currency against the USD which leads to a reduction in the purchasing power of nominal cash balances. Consequently, the value of real cash balances depreciates, and consumers buy fewer quantities of products with the given amount of holding in hand (Mahmood et al., 2013). It is widely accepted that an inflation rate of around $2-3 \%$ is considered beneficial for sustained economic growth in developing countries; however, a higher inflation rate is completely destructive to the health of an economy (Khan and Gill, 2010). During periods of high inflation, consumers usually prefer to buy fewer amounts of commodities for consumption in the marketplace. Therefore, commodities remain unsold with the sellers, which minimizes the profit margin of the industrial units, which in turn, increases unemployment in the economy.

Unemployment is regarded as one of the core issues of worldwide economies. According to an ILO report (2017), 5.7 percent of the globe's total labor force was unemployed. Nonetheless, this serious issue is particularly acute in South Africa and this economy requires sustained economic growth to rapidly reduce the 
high unemployment rate in current periods. According to the Quarterly Labor Force Survey (Q2: QLFS, 2019), the unemployment of South Africa in 2019Q2 was $29.0 \%$ which indicates that the unemployment rate grew by $1.4 \%$ from $2019 \mathrm{Q} 1$. The survey also reported that there were 6.7 million people who were unemployed in South Africa aged 15-64 years. Out of 6.7 million unemployed people, 57\% persons had a below metric education level, $33.4 \%$ persons had a metric level education, $2.2 \%$ persons had a university education, and $6.9 \%$ persons had completed tertiary education, whereas; the remaining $0.5 \%$ persons were unemployed having higher education (Q2: QLFS, 2019). These statistics highlight that the educated youth unemployment rate has been continuously increasing over the last two decades.

The scenario of unemployed educated youth is alarming from different perspectives. It should be noted that in developing economies like South Africa, where the major portion of public income is from exchange rate earnings via mainly exporting precious metals, mineral fuels, electrical equipment, plastic articles, etc., the foreign exchange rate is the key indicator in the whole economic system. There is no doubt that a stable exchange rate is necessary for achieving macroeconomic stability in the long-term; however, the exchange rate instability adversely influences the economy in the short run. Consequently, the exchange rate fluctuation should be empirically investigated due to its significant relationship to the behavior of investors as it causes risk-averse investors who prefer to invest less; consequently, this element causes a rise in the unemployment rate (De Grauve, 1988). The basic reasons for unemployment in South Africa include poor education and training programs, labor demand-supply mismatching, the involvement of trade unions in government activities, the effects of global recessions, lack of enhancing entrepreneurship, and poor economic performance. The severity of unemployment in South African's economy is mainly connected with many social problems, namely, poverty, corruption, crime, murder, violence, and degradation (Kingdon and Knight, 2004; Levinsohn, 2008).

The connection between inflation and unemployment is negative according to the Phillips curve, and this association has been confirmed in the findings of (Kaur, 2014; Zivanomoyo and Mukoka, 2015). According to the Phillips curve (1958), the correlation between inflation-unemployment is negative in the shortterm; however, both the variables are not related to each other in the long-term. Similarly, the association between unemployment and economic growth can be historically referred from the famous Okun's law (1962), which states that a $1 \%$ fall in GDP is associated with a less than $2 \%$ rise in the unemployment rate; therefore, we can say that the relationship between the two variables is inverse. 
However, there are mixed findings exist about the correspondence between exchange rate-unemployment in the empirical macroeconomics literature. Some empirical studies have concluded that the connection between exchange rate vs. unemployment is inverse and these studies include (Chowdhury and Hossain, 2014; Kaur, 2014; Bakhshi and Ebrahimi, 2016); however, other empirical studies suggest that the relationship between the analyzed factors is positive, and this result has been confirmed from the findings of the study conducted by (Islam and Sajalal, 2019).

The economy of South Africa has the youngest and the fastest-growing population of youth across the world. In this economy, more than 12 million young people are severely affected due to the unavailability of job opportunities. Consequently, the new generation of South Africa is also missing predominant work skills; therefore, the youth rely on state grants ${ }^{6}$ for their livelihood. During the period 2008-2015, more than 2 Lac youth have lost their jobs in different organizations. Moreover, the economy of South Africa faces another loss to youth employment via the erosion of skills as well as human capital, leading towards prolonged unemployment. By 2015, the business confidence index of this economy fell to its lowest level in the last 22 years, showing a reduction in the gross output. To encourage the performance of local businesses, the government is focusing on the hiring of entry-level employment of skilled personnel.

The World Bank observed that South Africa requires job-intensive growth and training programs to produce highly skilled workers to fulfill the rising labor market demands. Due to the lack of market information, it is quite hard for the unemployed population to search for better job opportunities in job markets. Furthermore, human resource opportunities, organization structures, and working processes also lead to unemployed persons being locked out of employment opportunities because employers are interested in hiring experienced and skilled workers. The government of South Africa has initiated a Youth Wage Subsidy program to provide certain incentives to different industries to hire first-job seekers by subsidizing their recruitment costs. However, the problem of youth unemployment has still not satisfactorily been addressed, and recently, this problem extends beyond the youth population, and it is now impacting people of different age-groups. Due to the emergence of the financial crisis between mid-2007 and early 2009, the South African economy has been confronted with comparatively low levels of economic growth rates each year. The mean growth rate of South Africa for the period 2008-2016 was below $1.7 \%$, while the growth rate was

\footnotetext{
${ }^{6}$ In other words, more than 16 million persons are expected to completely depend on the public grants in the future.
} 
recorded below 1.7\% for the 2015-2016 fiscal year (South African Reserve Bank, 2016). The sustained poor economic growth rate in the last two decades has negatively affected the performance of the job market in South Africa (Maswanganyi, 2014). It is noteworthy to note that economic growth is of considerable significance in reducing the large-scale unemployment in the economy; however, it would not suffice since economic growth solely can't address all the key drivers that contribute to unemployment reduction. Accordingly, it is necessary to devise and implement sound economic policies that help to initiate investment and job-creation programs at the national level; consequently, these programs will enable the economy to create more job opportunities for its youth at a large-scale and the economic growth will also accelerate (Osinubi, 2005). Therefore, the current study is the first endeavor to explore the economic consequences of severe unemployment on the economic performance of South Africa and how unemployment influences these variables in multiple ways. In simple words, the main purpose of this paper is to analyze the dynamic effects of unemployment on the real GDP growth rate, inflation rate, and exchange rate in South Africa. Following are the key research questions of this paper:

- Is there any long-run connection between unemployment vs. economic growth in South African's economy?

- Is there any short-run connection between unemployment vs. economic growth in South African's economy?

- Is there any casual flow between the unemployment rate and the independent variables (i.e., real GDP, inflation rate, exchange rate) in South African's economy?

The remaining study will proceed as mentioned: Literature review is presented in Section 2, the data and its sources are described in Section 3, Section 4 highlights the model specification and the econometric strategy employed, Section 5 explains the step-by-step findings, and Section 6 concludes the whole study along with policy recommendations.

\section{Literature Review}

The economic impact of real GDP, inflation rate, and exchange rate on unemployment for worldwide economies has been the center of attention for economists, policymakers, and researchers for decades. In the available macroeconomics literature, various studies are investigating the economic effects of these variables on unemployment for both developing and developed economies. Chowdhury and Hossain (2014) considered the influence of economic growth, exchange rate, and inflation rate on unemployment for the economy of Bangladesh 
by applying the annual time-series data over the 2000-2011 period. Utilizing the simple linear regression model, the study proved that the consequence of inflation on unemployment was positive; however, the effect of real GDP and exchange rate on unemployment was negative. The authors recommended an equal distribution of income among various sections of the society with the purpose to accelerate the economic advancement of the country. Another related study attempted by Thayaparan (2014) emphasized the impact of economic growth and inflation rate on unemployment for Sri Lankan's economy by taking the annual data covering the period 1990-2012. The analysis showed that the influence of economic growth and the inflation rate on unemployment was significantly indirect. Furthermore, the Granger causality test reported that there was a bidirectional causality between inflation-unemployment, whereas there was a unidirectional causality between real GDP and rising prices.

Aurangzeb and Asif (2013) investigated the effects of real GDP, inflation, exchange rate, and population growth rate on unemployment for three selected Asian economies: Pakistan, China, and India. Using the annual data from 1980 to 2009, the authors utilized the Johansen approach to co-integration to detect the long-term association among these variables and concluded that the variables were co-integrated. The findings of Granger causality suggested that there was no bidirectional causality among the variables; however, a unidirectional causality was found between different pairs, namely from GDP growth rate to unemployment plus from unemployment to exchange rate. Another study carried out by Al-Habees and Abu Rumman (2012) explored the link between unemployment vs. GDP in Arab economies from 2006 to 2011. They found that the fast growth rate and the gradual decline in the unemployment rate were a very promising trend towards development, but this was counter to the presence of a strong correlation between GDP and unemployment. Hossain et al. (2012) explored the economic growthinflation nexus in Bangladesh by considering time-series data from 1978 to 2010. The Johansen approach to co-integration reported that there was no co-integrating association between the two variables. Furthermore, the findings of Grange causality indicated a unidirectional causality running from inflation to real GDP. In order to examine the association between unemployment and exchange rate, Frenkel and Ros (2006) made an attempt to scrutinize the role of the exchange rate in unemployment situations for Mexico, Brazil, Argentina, and Chile. The authors found that the exchange rate significantly influences unemployment in these economies. A similar empirical study conducted by Chang (2011) explored the influence of exchange rate fluctuations on unemployment for Taiwan and S. Korea and concluded that the long-term equilibrium connection exists between the 
variables. The analysis also concluded that fluctuations in the exchange rate had a short-term influence on unemployment. However, the study of Mohammadi and Gholami (2008) declined the hypothesis of a significant connection between exchange rate-unemployment for Iran.

In the case of South Africa, an influential study conducted by Makaringe and Khobai (2018) examined the influence of unemployment on economic growth by considering data on a quarterly basis from 1994Q1 to 2016Q4. Employing the ARDL bounds test, the empirical findings demonstrated that there was a negative significant connection between unemployment vs. economic growth both in the short and long-run. To understand the unemployment-economic growth nexus in Bhutan, a study carried out by Tenzin (2019) examined the connection between unemployment, economic growth, and inflation over the 1998-2016 period. Applying the ARDL specification to cointegration, the findings suggested that there was no connection between economic growth-unemployment both in the short and long-run. Unemployment had a negative linkage with inflation in the short-run and a positive linkage between unemployment-inflation in the long-run. The analysis indicated that policymakers should emphasize different sectors to create employment opportunities to reduce youth unemployment.

A recent study attempted by Ellen and Abeti (2019) analyzed the influence of unemployment on economic growth for the Chinese economy over the period 1991-2018. Employing the ARDL bounds test to cointegration, the empirical results revealed that the association between unemployment-economic growth was negative in the short and long-term. The Granger causality results demonstrated that there was no causal linkage between the two factors. A most recent attempt made by Chuttoo (2020) explored the connection between unemployment vs. economic growth in Mauritius. Applying the ARDL cointegration approach, the results reported that there was a negative, but an insignificant connection between unemployment-economic growth in the short and long-run. The results supported the validity of Okun's law for this economy. A more recent study conducted by Dayioğlu and Aydın (2020) analyzed the association between unemployment, economic growth, inflation, and current account balance for Turkey using data on a quarterly basis for the 2000Q1-2020Q4 period. The study concluded that the association between unemployment vs. economic growth was negative. The symmetric causality test indicated that economic growth had a one-direction symmetrical causality connection from negative shocks to negative inflation shocks. When the association between variables was analyzed only with one-way or two-way causality, there was no association found; hence, the causality must be analyzed asymmetrically for the validity of Okun's law. 
The review of the literature highlights the importance of the macroeconomic variables under discussion and their relationship with each other in the context of different economies of the world. However, there are some contradictory results found in the available literature about the relationship between these macroeconomic variables, especially between the pair exchange rateunemployment. Therefore, this study not only attempts to investigate the underlying relationship among these variables for the South African economy, but also to fill the huge gap in the existing macroeconomics literature on the topic for the economy of South Africa.

\section{Data Description}

The dataset employed in the current study comprises annual observations on unemployment, real GDP, inflation rate, and the exchange rate for the economy of South Africa over the period 1980-2018. The economic growth and exchange rate variables have been transformed to logarithmic form to avoid spurious regression results and to suit the operation of variance in the econometric analysis. Another key aspect of such logarithmic transformations is that it allows the researchers to interpret the parameter estimates as direct elasticities. On the contrary, the unemployment and inflation rate variables ${ }^{7}$ are not transformed to logarithmic form as they are primarily expressed in percentages. The real GDP is taken as a proxy for the economic growth of South Africa, which is calculated in the 2010 USD to eliminate the impact of inflationary trends. Secondary data on the economic growth is drawn mainly from the WDI (World Development Indicators, 2019) database. The inflation rate is proxied by the CPI (Consumer Price Index), where data on the inflation rate is extracted from the ILO (International Labour Organization, 2019) database. Besides, the exchange rate is expressed in units of South Africa Rand to USD (Rand per US\$), where data on the bilateral exchange rate is generated from the (OECD Main Economic Indicators, 2019). Finally, the unemployment rate in South Africa comprises the proportion of unemployed people as a \%age of the total workforce. This indicator comprises the people (aged 15 years and above) who don't have work but are actively searching for work. Data on unemployment in South Africa is taken from the World Bank (2019) databank, and the quality of data has been assured from the ILO statistics and databases (2019). Figure 1 displays the historical plot of these variables suggested in the econometric model over the sample period, which describes a similar upward trend in each of the variables, except for the inflation rate. More specifically, the time-series plots

\footnotetext{
${ }^{7}$ We do not need to transform these original variables into logarithmic form because we will not be able to interpret such kind of transformation for policy purposes.
} 
reveal that the examined variables are trend-stationary; however, a formal unit root test (e.g., the ADF test) is needed for the confirmation of a non-stationary timeseries.

Fig 1: Plot of Variables over the sample period, 1980-2018 (Source: Results extracted fromEViews 10)
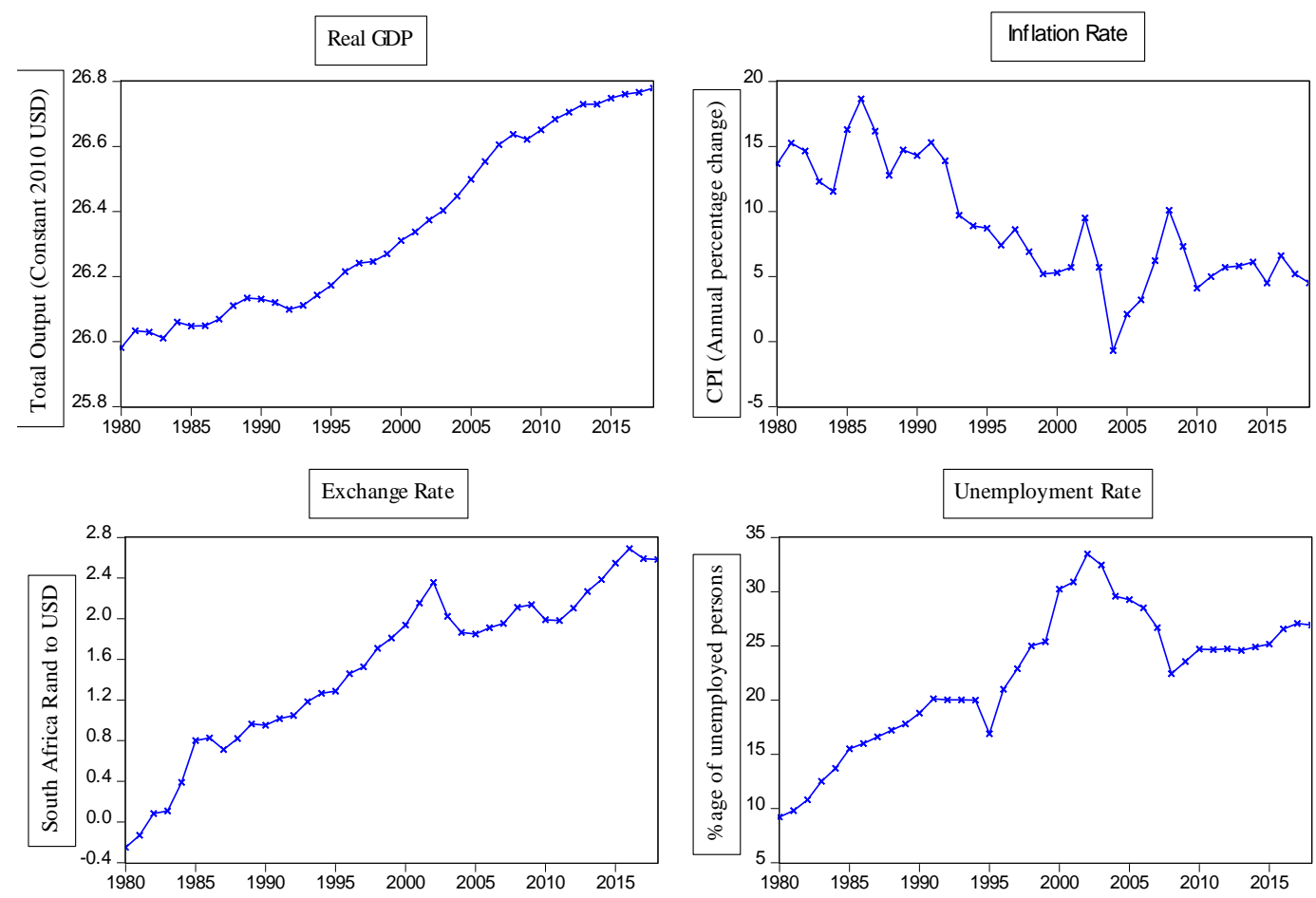

\section{Model Specification and Econometric Methodology}

\subsection{Econometric Model}

The present study investigates the influences of the growth rate of real GDP, inflation rate, and the exchange rate on unemployment in the economy of South Africa by utilizing the VAR ( $p$ ) model developed by Sims (1980). Therefore, these variables are purely selected in accordance with the theory of macroeconomics and empirical evidence. The significance of the association among these variables has been acknowledged and emphasized in the macroeconomic theory (e.g., Tunah, 2010; Sanchez and Liborio, 2012; Chowdhury and Hossain, 2014; Kaur, 2014; Tanha, 2018; Islam and Sahajalal, 2019). The specification of the linearlogarithmic regression model can be specified in Equation (1) as follows:

$U N E M P_{t}=\beta_{0}+\beta_{\text {rgdp }} \ln R G D P_{t}+\beta_{\text {inf }} I N F_{t}+\beta_{\text {ex }} \ln E X_{t}+\varepsilon_{t}$ 
Where:

$U N E M P_{t}=$ The unemployment rate in period $t$

$\ln R G D P_{t}=$ The log-transformed real GDP in period $t$

$I N F_{t}=$ The inflation rate in period $t$

$\ln E X_{t}=$ The log-transformed exchange rate in period $t$

$\beta_{0}=$ Constant term/y-intercept

$\beta_{i}=$ The coefficients of explanatory variables

$\varepsilon_{t}=$ The disturbance term of the model

$t=$ The sampling period (1980-2018).

\subsection{Econometric Methodology}

A general VAR $(p)$ model for various endogenous variables is a system for outcomes at a given time span and time-lagged explanatory variables, with $p$ in parenthesis indicating the number of lags included in the analysis. The differentiation between endogenous and exogenous variables in a model system has been heavily critiqued by Christopher Sims (1980). Sims's view suggests that if there is a problem of simultaneity among variables, then there should be no distinction between the class of exogenous and endogenous variables in VAR systems. Hence, the variables suggested in the study are considered endogenous in the VAR system. One of the best characteristics of the VAR model is its capability of capturing the joint dynamics of multiple time series. On the one side, VAR models appear to be straightforward multivariate generalizations of univariate AR models. On the other side, such models turn out to be one of the key empirical tools in modern applied macroeconomics. More formally, suppose $Y_{t}$ is a vector with a value of $n$ variables in the $\operatorname{VAR}(p)$ system at the sample period $t$ :

$Y_{t}=\left[Y_{1, t}, Y_{2, t}, Y_{3, t}, \ldots, Y_{n, t}\right]$

A $p^{\text {th }}$ order VAR system is known as the generalization of a one-variable $\mathrm{AR}(p)$ process to $n$ variables which can be stated as follows:

$Y_{t}=G_{0}+G_{1} Y_{t-1}+G_{2} Y_{t-2}+G_{3} Y_{t-3}+\ldots \ldots+G_{p} Y_{t-p}+e_{t}$

Where:

$G_{0}=(n * 1)$ vector of constants

$G_{i}=(n * n)$ matrix of coefficients 
$e_{t}=(n * 1)$ vector of white noise innovations

The white noise innovations are very important which means that the stochastic error terms are serially uncorrelated and have finite variance. That is,

$E\left(e_{t}\right)=0$

$E\left(e_{t} e_{\tau}{ }^{\prime}\right)=\left[\begin{array}{c}\Omega \text { if } t=\tau \\ 0, \text { otherwise }\end{array}\right]$

In matrix notation,

$\left(\begin{array}{l}\varepsilon_{1 t} \\ \varepsilon_{2 t}\end{array}\right) \sim\left[\left(\begin{array}{l}0 \\ 0\end{array}\right),\left(\begin{array}{cc}\sigma^{2} & 0 \\ 0 & \sigma^{2}\end{array}\right)\right]$

We use the OLS (Ordinary Least Squares) methodology to estimate the VAR model; therefore, we are required to ensure that all the variables are stationary to avoid the misleading regression results associated with unit root tests.

\subsubsection{Testing Stationarity}

The opening step of the time-series analysis is to check for the stationarity property of the variables under consideration. This property of a time series is critical to the construction of a VAR analysis because, in the presence of a unit root, a model's statistics, for instance, correlations and averages will not correctly notify the appropriateness of the model. VAR models are applied only if the considered variables are I (1). Our study adopts the famous ADF (Augmented Dickey-Fuller, 1981) procedure to check for the presence of unit roots among the variables. The null hypothesis $\left(H_{0}\right)$ of this testing procedure is that the series under consideration is a non-stationary process as compared to the alternative hypothesis $\left(H_{l}\right)$ which states that the particular series is stationary at level. If the ADF t-test statistical value is less than the t-test critical value, $H_{0}$ is rejected; indicating that the particular time-series does not require any kind of transformation to attain stationarity and the time-series modeling can proceed one step forward to the step of selecting the appropriate lag length.

\subsubsection{Lag Specification Criteria}

Lag specification criteria introduce the number of lagged values in a timeseries setup that will be selected as predictors in VAR $(p)$ specifications. Lütkepohl (2005) documented that employing extremely short lags $(p)$ can produce in autocorrelated error terms; consequently, the proposed econometric model will be poorly specified as residuals may not satisfy the properties of white-noise error terms. In contrast, if the number of lags $(p)$ is very large, many $d . f$ will be lost. In 
other words, the inclusion of too many lags in the VAR system results in overfitting (i.e., the over-parameterized model); hence, it will cause a rise in meansquare-forecast errors in the VAR system. Therefore, the lags number should be adequate for the residuals to constitute individual white-noises when considering stationary variables in VAR models. The best way is to fit general VAR $(p)$ models with different lag lengths (e.g., $p=0,1,2,3, \ldots, p_{\max }$ ) and after that select the value of lag order which ensures the best model selection criteria. In practice, different statistics, for instance, the Akaike Information Criterion (AIC), Schwarz Information Criterion (SIC), and the Hannan-Quinn Criterion $(H Q)$ are adopted as suggested by Vrieze (2012). According to Lütkepohl (2005), the number of lags associated with the lowest value of a typical criterion is chosen for VAR analyses.

\subsubsection{Development of the VAR Model}

The specification of VAR models employed in the setup of multivariate time-series is that each endogenous variable in the system, over a selected sample period, is a linear function of the most recent lag of both itself and the other endogenous variables. More specifically, the variable (say $X_{t}$ ) that is influenced by the current and lagged values of another variable (say $Y_{t}$ ) and concurrently, the variable (say $Y_{t}$ ) that is influenced by the current and lagged (past) realizations of another variable (say $X_{t}$ ) in the given model system. An illustration of a generalized VAR model with four endogenous variables can be represented as given:

$U N E M P_{t}=\beta_{U N E M P}+\sum_{i=1}^{k} \alpha_{i} U N E M P_{t-i}+\sum_{j=1}^{k} \beta_{j} \operatorname{lnRGDP_{t-j}+}$

$\sum_{m=1}^{k} \phi_{m} I N F_{t-m}+\sum_{n=1}^{k} \varphi_{n} \ln E X_{t-n}+u_{1 t}$

$\ln R G D P_{t}=\beta_{R G D P}+\sum_{i=1}^{k} \alpha_{i} U N E M P_{t-i}+\sum_{j=1}^{k} \beta_{j} \ln R G D P_{t-j}+$

$\sum_{m=1}^{k} \phi_{m} I N F_{t-m}+\sum_{n=1}^{k} \varphi_{n} \ln E X_{t-n}+u_{2 t}$

$I N F_{t}=\beta_{I N F}+\sum_{i=1}^{k} \alpha_{i} U N E M P_{t-i}+\sum_{j=1}^{k} \beta_{j} \ln R G D P_{t-j}+\sum_{m=1}^{k} \phi_{m} I N F_{t-m}+$

$\sum_{n=1}^{k} \varphi_{n} \ln E X_{t-n}+u_{3 t}$

$\ln E X_{t}=\beta_{E X}+\sum_{i=1}^{k} \alpha_{i} U N E M P_{t-i}+\sum_{j=1}^{k} \beta_{j} \ln R G D P_{t-j}+\sum_{m=1}^{k} \phi_{m} I N F_{t-m}+$ $\sum_{n=1}^{k} \varphi_{n} \ln E X_{t-n}+u_{4 t}$

More specifically, a four variables VAR(1) model for unemployment, real GDP, inflation, and exchange rate has the general matrix specification for regression with multivariate outcomes as follows: 
$\left[\begin{array}{c}Y_{U N E M P, t} \\ \ln Y_{R G D P, t} \\ Y_{I N F, t} \\ \ln Y_{E X, t}\end{array}\right]=\left[\begin{array}{c}\beta_{U N E M P} \\ \beta_{R G D P} \\ \beta_{I N F} \\ \beta_{E X}\end{array}\right]+\left[\begin{array}{c}A_{11} A_{12} A_{13} A_{14} \\ A_{21} A_{22} A_{23} A_{24} \\ A_{31} A_{32} A_{33} A_{34} \\ A_{41} A_{42} A_{43} A_{44}\end{array}\right]\left[\begin{array}{c}Y_{U N E M P, t-1} \\ \ln Y_{R G D P, t-1} \\ Y_{I N F, t-1} \\ \ln Y_{E X, t-1}\end{array}\right]+\left[\begin{array}{c}\varepsilon_{U N E M P, t} \\ \varepsilon_{R G D P, t} \\ \varepsilon_{I N F, t} \\ \varepsilon_{E X, t}\end{array}\right]$

In scalar notation, the above VAR (1) model arranged in the matrix algebra can be rewritten as:

$Y_{U N E M P, t}=\beta_{U N E M P}+A_{11} Y_{U N E M P, t-1}+A_{12} \ln Y_{R G D P, t-1}+A_{13} Y_{I N F, t-1}+$

$A_{14} \ln Y_{E X, t-1}+\varepsilon_{U N E M P, t}$

$\ln Y_{R G D P, t}=\beta_{R G D P}+A_{21} Y_{U N E M P, t-1}+A_{22} \ln Y_{R G D P, t-1}+A_{23} Y_{I N F, t-1}+$

$A_{24} \ln Y_{E X, t-1}+\varepsilon_{R G D P, t}$

$Y_{I N F, t}=\beta_{I N F}+A_{31} Y_{U N E M P, t-1}+A_{32} \ln Y_{R G D P, t-1}+A_{33} Y_{I N F, t-1}+$

$A_{34} \ln Y_{E X, t-1}+\varepsilon_{I N F, t}$

$Y_{E X, t}=\beta_{E X}+A_{41} Y_{U N E M P, t-1}+A_{42} \ln Y_{R G D P, t-1}+A_{43} Y_{I N F, t-1}+A_{44} \ln Y_{E X, t-1}+$

$\varepsilon_{E X, t}$

As given in the reduced form VAR model in Equations (9)-(12), the predictors of each outcome are similar, which are the past values of unemployment, real GDP, inflation rate, and exchange rate, respectively. Intercept terms of the VAR system are shown by $\beta$ terms, parameter estimates of the lagged variables are represented by subscripted $A$ values, whereas $\varepsilon_{i, t}$ is the impulses in VAR models. The equations can be estimated by selecting the OLS estimation technique due to the identical terms of explanatory variables on the R.H.S of Equations (9)-(12), and the coefficient estimates of these equations will be consistent, efficient plus equivalent to GLS since these expressions have identical regressors.

\subsubsection{Conditions for Stationarity}

$\operatorname{A~VAR~}(p)$ process is said to be covariance-stationary (stable) and invertible if the $n p$ roots of the characteristic polynomial of the coefficients matrix $A$ are outside the unit imaginary circle. The characteristic polynomial is defined as the determinant of the lagged polynomial, which can be written in Equation (13) as follows:

$$
\operatorname{det}\left(I_{n}-G_{1} L-G_{2} L^{2}-G_{3} L^{3}-\cdots-G_{p} L^{p}\right)=0 \text {. }
$$

As we know that the EViews 10 statistical software package determines the inverse roots of the characteristic $A R$ polynomial, it should thus lie inside the unit 
imaginary circle. If the VAR system is not stable, then impulse response S.Es are not statistically valid.

\subsubsection{Testing for Residual Autocorrelation}

After the development of the VAR model, the subsequent step is to establish if the adopted VAR model anticipates a reliable description of the examined data. In VAR $(p)$ models, this diagnostic checking is executed by inspecting the residuals because autocorrelation of the residual terms reveals that there is some important information that has not yet been reckoned in the selected model. In VAR models, the Lagrange Multiplier (LM) test is the standard diagnostic check for diagnosing residual autocorrelation. The $H_{0}$ of the LM test is that there is no residual autocorrelation; conversely, the $H_{1}$ states that there is serial autocorrelation as mentioned by Lütkepohl (2005).

\subsubsection{Testing for Heteroscedasticity}

One of the main assumptions of the VAR analysis is that the variance of the stochastic error terms should remain constant across selected observations. If the stochastic disturbance terms do not have constant variance, then we say that residuals are heteroscedastic in nature, and we have the issue of heteroscedasticity. In this case, the OLS parameter estimates are unbiased but inefficient. Additionally, the variances and standard errors are biased; consequently, lead to higher calculated values of both $t$ and $F$-statistics. Therefore, these kinds of statistical tests are no longer reliable for the testing of a null hypothesis. In VAR models, White's heteroscedasticity test is the famous diagnostic check for testing heteroscedasticity. The $H_{0}$ of White's test is that residual's variance is constant over time, and the $H_{1}$ is that the variance of the residual is changing over time.

\subsubsection{Evaluating the Granger Causality Test}

The VAR specification illustrates the joint generation procedure of various endogenous variables over the sample period; consequently, this model can be estimated for exploring relationships between different pairs of variables. Granger causality is, therefore, one kind of association between any two time-series variables (Granger, 1969). The fundamental notion of Granger causality in Time Series Econometrics was developed by Granger (1969) which states that a timeseries $Y_{t}$ is said to Granger cause another time-series $X_{t}$ if $X_{t}$ series can be forecasted with greater accuracy by considering lagged information of the time series $Y_{t}$ instead not employing such lagged information, keeping all other terms of the model constant. The null and alternative hypotheses for pair-wise Granger causality are given below: 
$H_{0}: \sum_{i=1}^{n} \beta_{i}=0$

$H_{1}: \sum_{i=1}^{n} \beta_{i} \neq 0$

The $H_{0}$ of Granger causality is rejected if all coefficient estimates for the past values of time series $X_{t}$ are statistically significant, where the standard $F$ statistic on coefficients restriction is used for decision purposes. Moreover, if the calculated $F$-statistical value is higher than the $F$-statistical critical value, we reject $H_{0}$ and conclude that time series $X_{t}$ causes $Y_{t}$.

\subsubsection{The Impulse Response Function}

As we know that all individual parameter estimates associated with lagged predictors in the estimated VAR analysis are generally not easy to interpret for policy analysis, econometricians often suggest that the impulse response function (IRF) should be analyzed. Impulse responses capture the effects of structural shocks on the endogenous variables of VAR systems in the future. Each response comprises the effect of a particular shock on one of the endogenous variables at impact $t, t+1$, etc. If a VAR model is stationary, then the $Y_{t}$ vector can be demonstrated as a sum of all of the past white-noise shocks $\left(e_{t}\right)$, which is generally known as the moving-average representation denoted by $\operatorname{VMA}(\infty)$. For this purpose, we transform our structural autoregressive vector into a sum of shocks, which is commonly known as Wold representation. The general expression of the $\mathrm{VMA}(\infty)$ representation is given in Equation (14) below.

$Y_{t}=\mu+G(L)^{-1} e_{t}$

Where: $\mu=G(L)^{-1} G_{0}$

$Y_{t}=\mu+\left(I_{n}+\psi_{1} L+\psi_{2} L^{2}+\psi_{3} L^{3}+\cdots\right) e_{t}$

$Y_{t}=\mu+e_{t}+\psi_{1} e_{t-1}+\psi_{2} e_{t-2}+\psi_{3} e_{t-3}+\cdots$

$Y_{t}=\mu+\sum_{i=0}^{\infty} \psi_{i} e_{t-i}$

Where:

$\psi_{i}=(n * n)$ matrix of coefficients

$\psi_{0}=$ identity matrix

We can express VAR models as a $\operatorname{VMA}(\infty)$ representation with the standard VAR's error terms as follows:

$\left[\begin{array}{l}Y_{t} \\ Z_{t}\end{array}\right]=\left[\begin{array}{l}\bar{Y}_{t} \\ \bar{Z}_{t}\end{array}\right]+\sum_{i=0}^{\infty}\left[\begin{array}{l}a_{11} a_{12} \\ a_{21} a_{22}\end{array}\right]^{i}\left[\begin{array}{l}e_{1 t-i} \\ e_{2 t-i}\end{array}\right]$ 


\subsubsection{Variance Decomposition}

The idea of variance decomposition provides the \%age of unexpected change in each endogenous variable that is produced by impulses from other endogenous variables in VAR systems. Therefore, the variance decomposition tells the researchers that how much change in an endogenous variable occurs due to its own impulse and how much change occurs due to shocks to other endogenous variables in VAR models. In structural regressions, most of the change in a variable occurs due to its own shock but, as the lagged variables' effect starts kicking in, the $\%$ age of the effect of other innovations increases over time. It is noted that this concept enables assessment of the economic significance of this impact as a \%age of the forecast error for a variable sum to unity (or 100 percent). The orthogonolisation procedure of VAR models decomposes the forecast error variance. For such objectives, reconsider the $\operatorname{VMA}(\infty)$ representation of the standard VAR model in the summarized notation as:

$X_{t}=\bar{X}+\sum_{i=0}^{\infty} \phi_{i} \varepsilon_{t-i}$

The $n$-period forecast error of the time series $X_{t}$ can be derived by starting from period- 1 as:

$$
\begin{aligned}
& X_{t+1}=\overline{\bar{X}}+\phi_{0} \varepsilon_{t+1}+\phi_{1} \varepsilon_{t}+\phi_{2} \varepsilon_{t-1}+\phi_{3} \varepsilon_{t-2}+\cdots \\
& E_{t} X_{t+1}=\overline{\bar{X}}+\phi_{1} \varepsilon_{t}+\phi_{2} \varepsilon_{t-1}+\phi_{3} \varepsilon_{t-2}+\cdots
\end{aligned}
$$

The 1-period forecast error is:

$X_{t+1}-E X_{t+1}=\phi_{0} \varepsilon_{t+1}$

The 2-period forecast error is:

$X_{t+2}-E X_{t+2}=\phi_{0} \varepsilon_{t+2}+\phi_{1} \varepsilon_{t+1}$

The 3-period forecast error is:

$$
X_{t+3}-E X_{t+3}=\phi_{0} \varepsilon_{t+3}+\phi_{1} \varepsilon_{t+2}+\phi_{2} \varepsilon_{t+1}
$$

Finally, the $n$-period forecast error can be written as:

$$
\begin{aligned}
& X_{t+n}-E X_{t+n}=\phi_{0} \varepsilon_{t+n}+\phi_{1} \varepsilon_{t+n-1}+\phi_{2} \varepsilon_{t+n-2}+\cdots+\phi_{n-1} \varepsilon_{t+1}= \\
& \sum_{i=0}^{n-1} \varepsilon_{t+n-i}
\end{aligned}
$$




\section{Empirical Results}

\subsection{Stationary Test Results}

VAR models can be applied to only those time-series that are $I(0)$ or $I(1)$ because we assume that all the time series must be stationary. In order to examine this fundamental issue, the ADF test devised by Dickey and Fuller (1979) is applied to check for the stationarity of each individual time-series. The following version of the ADF test given in Equation (23) is proposed due to the significant estimates for the inclusion of the intercept term, and the data-generating process also confirms the same finding (see, Figure 1).

$\Delta Y_{t}=\alpha_{0}+\gamma Y_{t-1}+\sum_{i=1}^{p} \beta_{i} \Delta Y_{t-i}+u_{t}$

The ADF test results report that all variables under analysis are $I$ (1); therefore, we accept our null hypothesis which states that the particular time-series is non-stationary at the level. Hence, we have differenced all variables one time to make them stationary for the application of the VAR analysis. The findings of the proposed versions of the ADF test have been given in Table 1.

Table 1: ADF test results

\begin{tabular}{cccccc}
\multicolumn{5}{c}{ Model: $\Delta \boldsymbol{Y}_{\boldsymbol{t}}=\boldsymbol{\alpha}_{\mathbf{0}}+\gamma \boldsymbol{Y}_{\boldsymbol{t}-\mathbf{1}}+\boldsymbol{\alpha}_{\mathbf{2}} \boldsymbol{t}+\sum_{\boldsymbol{i = 1} \mathbf{1}}^{\boldsymbol{p}} \boldsymbol{\beta}_{\boldsymbol{i}} \Delta \boldsymbol{Y}_{\boldsymbol{t}-\boldsymbol{i}}+\boldsymbol{u}_{\boldsymbol{t}} ; \boldsymbol{H}_{\mathbf{0}}: \boldsymbol{\gamma}=\mathbf{0} ; \boldsymbol{H}_{\boldsymbol{a}}: \boldsymbol{\gamma}>\mathbf{0}$} \\
\hline ADF tests at levels & \multicolumn{3}{c}{ ADF tests at first differences } \\
\hline Variables & Constant & $\begin{array}{c}\text { Constant and } \\
\text { trend }\end{array}$ & Constant & $\begin{array}{c}\text { Constant and } \\
\text { trend }\end{array}$ & Decision \\
\hline$U N E M P_{t}$ & -2.053655 & -1.437860 & $-5.034416^{*}$ & $-5.225253^{*}$ & $\mathrm{I}(1)$ \\
$\ln R G D P_{t}$ & 0.551555 & -2.511744 & $-4.570607^{*}$ & $-4.697066^{*}$ & $\mathrm{I}(1)$ \\
$I N F_{t}$ & -0.778407 & -1.075108 & $-2.959468^{* *}$ & $-5.248161^{*}$ & $\mathrm{I}(1)$ \\
$\operatorname{lnE} X_{t}$ & -2.184791 & -2.857992 & $-4.534003^{*}$ & $-4.698363^{*}$ & $\mathrm{I}(1)$ \\
\hline
\end{tabular}

Note: '*' and '**' represent significance at the $1 \%$ and $5 \%$ level of significance, respectively, and also the rejection of the $H_{0}$ of non-stationary series. The optimal lag lengths (i-e. $k=9$ ) were selected based on the SIC. Besides, the ADF test critical values are obtained from the Fuller (1976) values for all versions of the ADF regressions.

Source: Output from EViews 10

\subsection{Results of Lag Length Selection}

After achieving the stationarity of all time-series through first differencing, we have determined the optimal lag length as one using various lag selection criteria. This is not a surprising result because we have considered the annual timeseries data for estimation purposes, and the appropriate lag length of one is most suitable as suggested in the Time Series Econometrics literature. Table 2 reports that the first lag was associated with the minimum $A I C$ and $H Q$ reported values; however, the zero-lag was found with the minimum value of the $S C$ criterion. Consequently, we have determined an optimal lag length of one for estimation purposes. 
Table 2: Results of Lag Length Selection

\begin{tabular}{ccccccc}
\hline Lag & LogL & LR & FPE & AIC & SC & HQ \\
\hline $\mathbf{0}$ & -31.05372 & --- & $9.24 \mathrm{e}-05$ & 2.061983 & $2.241555^{*}$ & 2.123222 \\
$\mathbf{1}$ & -9.340655 & $37.03993^{*}$ & $6.66 \mathrm{e}-05^{*}$ & $1.725921^{*}$ & 2.623780 & $2.03217^{*}$ \\
$\mathbf{2}$ & -2.516676 & 10.03526 & 0.000119 & 2.265687 & 3.881833 & 2.816839 \\
$\mathbf{3}$ & 12.37810 & 18.39943 & 0.000142 & 2.330700 & 4.665134 & 3.126809 \\
$\mathbf{4}$ & 24.89469 & 12.51659 & 0.000220 & 2.535606 & 5.588327 & 3.576672 \\
\hline
\end{tabular}

Note: $(*)$ shows lag order chosen by the criterion (i.e., each test at $5 \%$ level)

Source: Output from EViews 10

\subsection{Results of Testing for Co-integration}

As we have four variables in the econometric model presented in Equation (1), there is a possibility of having more than one co-integrating vector in the system; meaning that the variables might possess several equilibrium associations with each other. If there exists more than one co-integrating relationship in the case when we have more than two variables in the model, we can't apply the EngleGranger (1987) approach of co-integration (Asteriou and Hall, 2007). The ADF test reports that the variables are $I(1)$; hence, the suitable co-integration approach is the Johansen and Juselius methodology (1990) (see, Khalid, 2017; Khalid and Khan, 2017). In our analysis, the findings report that the trace statistic value is less than the 5\% critical value; consequently, the model suggests no co-integrating relationship between two variables. The same outcomes have also been confirmed from the maximum eigenvalue statistic obtained from the estimation of the Johansen approach. Consequently, as we did not find any obvious evidence of cointegration $^{8}$ in the analysis, we can empirically estimate the unrestricted VAR model. The results of the Johansen methodology are given in Tables 3 and 4.

Table 3: Co-integration test results (Trace)

$H_{0}$ : There is no co-integration.

$H_{1}$ : There is co-integration.

\begin{tabular}{ccccc}
\hline No. of CE $(\mathbf{s})$ & Eigen Value & Trace Statistic & $\begin{array}{c}\text { 5\% } \\
\text { Critical Value }\end{array}$ & Prob.* \\
\hline None & .360847 & 41.66530 & 47.85613 & .1683 \\
At most 1 & .302066 & 25.10371 & 29.79707 & .1578 \\
At most 2 & .243417 & 11.79739 & 15.49471 & .1669 \\
At most 3 & .039119 & 1.476477 & 3.841466 & .2243 \\
\hline
\end{tabular}

Note: Trace test shows no co-integration at the 5\% level

(*) MacKinnon-Haug-Michelis (1999) p-values

Source: Output from EViews 10

\footnotetext{
${ }^{8}$ Also, we cannot go for the estimation of VECM.
} 
Table 4: Co-integration test results (Max Eigen Value)

$H_{0}$ : There is no co-integration.

$H_{1}$ : There is co-integration.

\begin{tabular}{ccccc}
\hline No. of CE $(\mathbf{s})$ & Eigen Value & $\begin{array}{c}\text { Maximum Eigen } \\
\text { Statistic }\end{array}$ & Critical Value & Prob.* \\
\hline None & .360847 & 16.56160 & 27.58434 & .6177 \\
At most 1 & .302066 & 13.30632 & 21.13162 & .4245 \\
At most 2 & .243417 & 10.32091 & 14.26460 & .1917 \\
At most 3 & .039119 & 1.476477 & 3.841466 & .2243 \\
\hline
\end{tabular}

Note: Maximum Eigen value test shows no co-integration at the 5\% level

(*) MacKinnon-Haug-Michelis (1999) p-values

Source: Output from EViews 10

\subsection{Results of the VAR Model Estimation}

VAR models were estimated by incorporating different lag lengths to find out the appropriate VAR model for the given endogenous variables. After repeating the estimation process several times, the VAR(1) model for all endogenous variables was ultimately selected and then estimated by deciding the optimal lag length of one (i-e. $p=1$ ). The whole estimation process was carried out with the use of the OLS estimation technique. The parameter estimates of the endogenous variables of the VAR (1) specification are given in Table 5.

\subsection{Results of Stability Conditions}

For $Y_{t}$ to be stable/stationary in the analysis of VAR models, the matrix polynomial in the shape of a lag operator must be invertible. In our study, the stationarity of the whole VAR system was basically visually judged utilizing the inverse roots of the characteristic polynomial with all the endogenous variables by selecting the optimal lag length of one. Figure 2 depicts the evaluation of the stability conditions of the VAR(1) system using a circular graphical plot of the autoregressive characteristic roots for all endogenous variables. The plot reveals that the inverse roots of the characteristic polynomial are all inside the unit imaginary circle, confirming that the proposed VAR(1) system is perfectly stable. For confirmation of the stable VAR(1) system, the modulus values in absolute terms of the complex roots are also computed. The results in Table 6 report that all the absolute modulus roots are smaller than unity, meaning that the VAR(1) system is stable. 
Table 5: VAR Model Results

\begin{tabular}{|c|c|c|c|c|}
\hline & D(UNEMP) & D(lnRGDP) & D(INF) & $\mathrm{D}(\ln \mathrm{EX})$ \\
\hline & -0.010887 & 0.000564 & -0.08144 & -0.005899 \\
\hline \multirow{3}{*}{ D(UNEMP (-1)) } & $(0.17265)$ & $(0.00195)$ & $(0.21616)$ & $(0.01365)$ \\
\hline & {$[-0.06306]$} & {$[0.28961]$} & {$[-0.40315]$} & {$[-0.43224]$} \\
\hline & -11.08628 & 0.282028 & 55.39096 & 1.239657 \\
\hline \multirow{3}{*}{ D(lnRGDP (-1)) } & (12.8369) & $(0.14478)$ & $(16.0718)$ & $(1.01481)$ \\
\hline & {$[-0.86362]$} & [1.94797] & [3.44647] & [1.22157] \\
\hline & -0.207413 & -0.001933 & -0.246118 & -0.019225 \\
\hline \multirow[t]{3}{*}{ D(INF (-1)) } & $(0.13063)$ & $(0.00147)$ & $(0.16354)$ & $(0.01033)$ \\
\hline & {$[-1.158784]$} & {$[-1.31194]$} & {$[-1.50491]$} & [-1.86169] \\
\hline & 5.913427 & -0.054818 & 9.401952 & 0.474760 \\
\hline \multirow[t]{3}{*}{$D(\operatorname{lnEX}(-1))$} & $(2 . .52853)$ & $(0.02852)$ & $(3.16571)$ & $(0.19989)$ \\
\hline & {$[2.33868]$} & {$[-1.92223]$} & [2.96993] & [2.37512] \\
\hline & 0.202127 & 0.017678 & -2.203021 & 0.009015 \\
\hline \multirow[t]{3}{*}{ Constant (C) } & $(0.45039)$ & $(0.00508)$ & $(0.56389)$ & $(0.03560)$ \\
\hline & [0.44878] & {$[3.48188]$} & {$[-3.90686]$} & [0.25319] \\
\hline & & \multicolumn{3}{|l|}{ Diagnostic Checks } \\
\hline$R^{2}$ & 0.195819 & 0.325364 & 0.378396 & 0.183300 \\
\hline Adj. $R^{2}$ & 0.095296 & 0.241035 & 0.300696 & 0.081212 \\
\hline SSR & 85.46493 & 0.010871 & 133.9658 & 0.534109 \\
\hline S.E. equation & 1.634252 & 0.018432 & 2.046077 & 0.129193 \\
\hline F-statistic & 1.948005 & 3.858251 & 4.869930 & 1.795514 \\
\hline Log likelihood & -67.98871 & 97.95126 & -76.30406 & 25.90362 \\
\hline AIC & 3.945335 & -5.024393 & 4.394814 & -1.129925 \\
\hline $\mathrm{SC}$ & 4.163027 & -4.806701 & 4.612506 & -0.912234 \\
\hline Mean dependent & 0.462703 & 0.020184 & -0.290541 & 0.073336 \\
\hline S.D. dependent & 1.718168 & 0.021157 & 2.446746 & 0.134782 \\
\hline
\end{tabular}

*Determinant resid covariance (dof adj.): 4.77E-05

Determinant resid covariance: $2.67 \mathrm{E}-05$

Log likelihood: -15.16964

AIC: 1.901062

SC: 2.771828

Note: S.Es in ( ) and t-stat in [ ]

(*) indicates the summary statistics for the VAR system as a whole.

Source: Output from EViews 10

Fig 2: Inverse Roots of AR Characteristic Polynomial (Source: Results extracted from EViews 10)

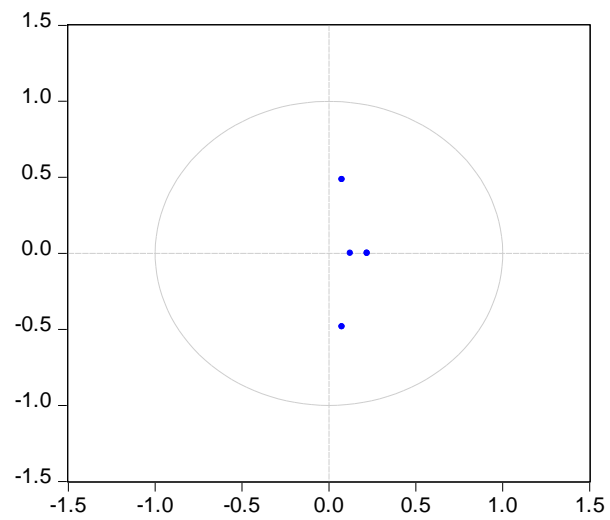


The Relationship between Unemployment and Economic Growth in South Africa: VAR Analysis

Table 6: Results of the VAR (1) Stability Condition Check Roots of Characteristic Polynomial

Endogenous Variables: $D(U N E M P) D(\ln R G D P) D(I N F) D(\ln E X)$

Exogenous Variable: $\mathrm{C}$

Lag Selection: 1

\begin{tabular}{llc}
\hline \multicolumn{1}{c}{ Roots } & Modulus \\
$\mathbf{0 . 0 7 6 9 6 9 - 0 . 4 8 3 9 3 i}$ & & $0.490026^{*}$ \\
$\mathbf{0 . 0 7 6 9 6 9}+\mathbf{0 . 4 8 3 9 3 i}$ & & $0.490026^{*}$ \\
$\mathbf{0 . 2 2 1 5 1 5}$ & & $0.221515^{*}$ \\
$\mathbf{0 . 1 2 4 3 3 0}$ & & $0.124330^{*}$ \\
\hline
\end{tabular}

Note: (*) represents that no root lies outside the unit circle.

Source: Output from EViews 10

\subsection{Results of Residual Autocorrelation}

Fig 3: Autocorrelations with Approximate 2 Stdard Error Bounds (Source: Results extracted from EViews 10)
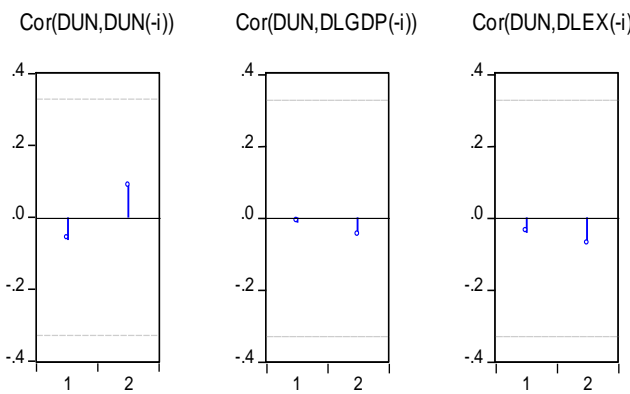

$\operatorname{Cor}(\mathrm{DUN}, \mathrm{DCPI}(-\mathrm{i}))$

Cor(DLGDP,DUN(-i))

$\operatorname{Cor}(\operatorname{DLGDP}, \mathrm{DLGDP}(-\mathrm{i}))$

Cor(DLGDP,DLEX(-i))

Cor(DLGDP,DCPI(-i))

Cor(DLEX,DUN(-i))
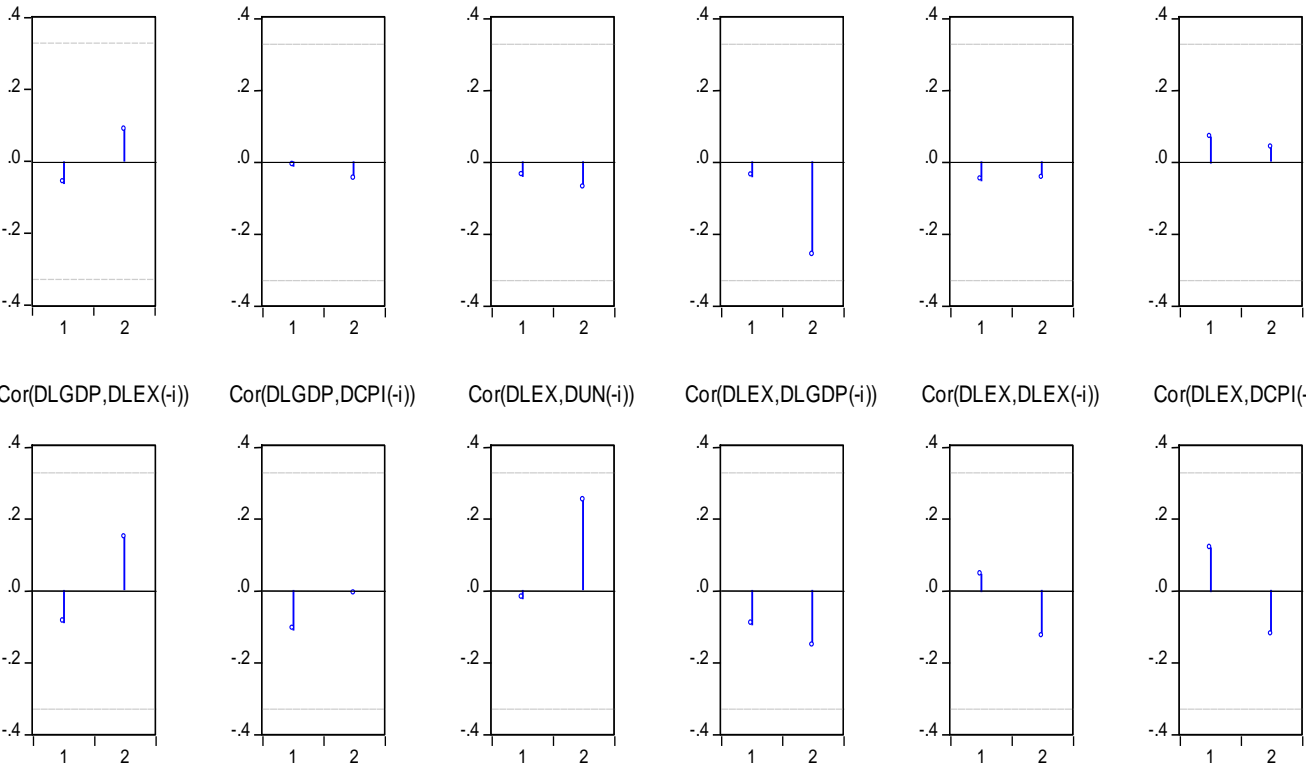

Cor(DLEX,DLGDP(-i))

Cor(DLEX,DLEX(-i))

Cor(DLEX,DCPI(-i))

Cor(DCPI,DUN(-i))

Cor(DCPI,DLGDP(-i)

Cor(DCPI,DLEX(-i))
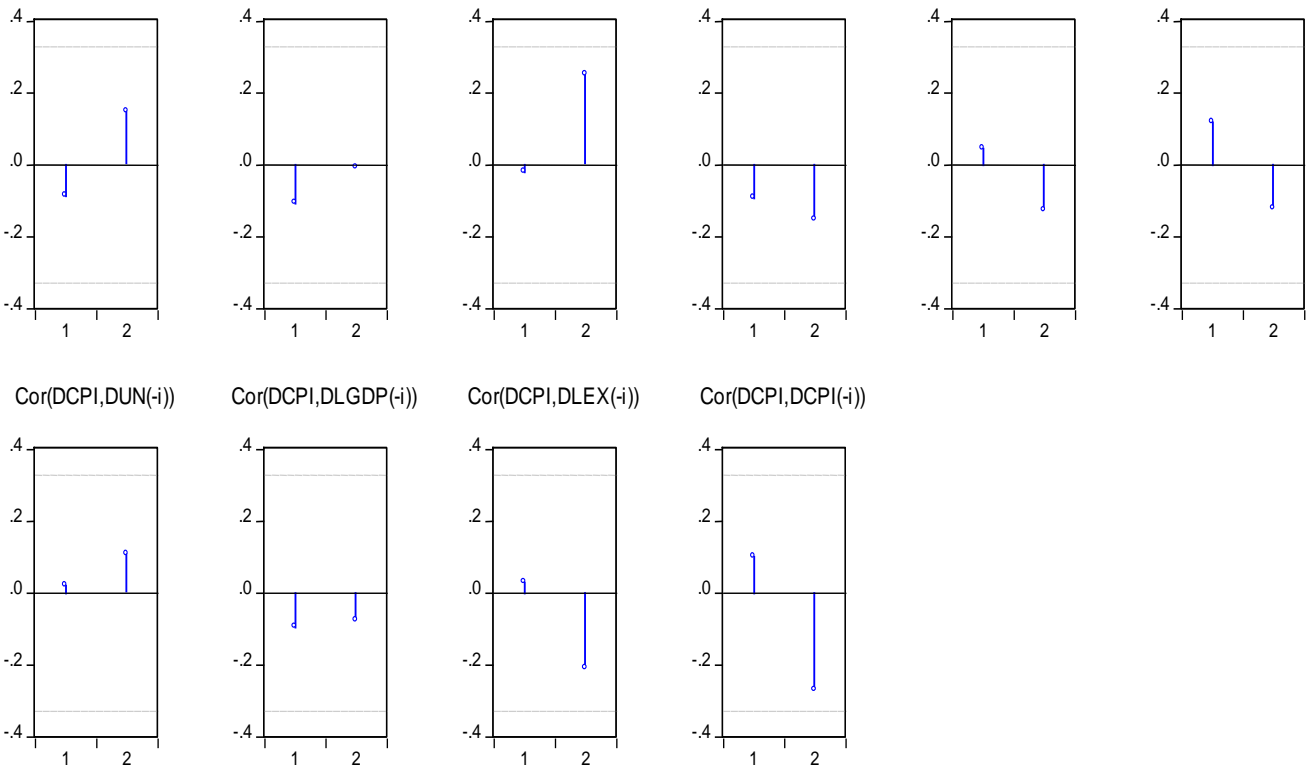

$\operatorname{Cor}(\mathrm{DCPI}, \mathrm{DCPI}(-\mathrm{i}))$

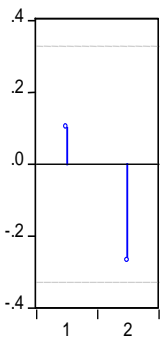


In order for the stationary VAR(1) model to be correctly specified in the present study, residuals need to be white-noises and therefore, should have no issue of autocorrelation. In order to examine the properties of the residuals in a more systematic way, we have made a visual inspection of the residuals through the correlogram specification. Figure 3 shows the cross correlograms (sample autocorrelations) for the fitted VAR(1) residuals for one included lag, where the plot depicts that the correlation for lag one is close to zero. Alternatively, the residual values of the model in all cases lie inside the two dotted standard error bound lines, suggesting that the residuals are white noises. We have also applied the conventional residual LM test to check for residual autocorrelation in the proposed VAR(1) system. The results in Table 7 report that the probability value is greater than $5 \%$ at lag one; therefore, we accept $H_{0}$. This result seems to be supportive of the idea that one lag is sufficient for the VAR estimation.

Table 7: Results of VAR Residual Serial Correlation LM Tests

\begin{tabular}{ccccccc}
\hline & \multicolumn{7}{c}{$H_{0}:$ No Serial Correlation at lag 1} \\
$H_{1}:$ Serial Correlation
\end{tabular}

*Edgeworth expansion corrected likelihood ratio statistic

Source: Output from EViews 10

\subsection{Results of Heteroscedasticity and Normality Tests}

The key assumption of VAR models is that the variance of the residual terms should remain constant over time ${ }^{9}$; therefore, we need to check for heteroscedasticity through the application of White's test. The findings presented in Table 8 report that the computed p-value of the chi-square statistic with $80 d$. $f$ is higher than 5\%; therefore, we accept the $H_{0}$ of homoscedasticity of residuals at the $5 \%$ significance level.

Table 8: VAR Residual Heteroscedasticity test results $($ Lags = 01)

$H_{0}:$ Errors are homoscedastic

$H_{1}$ : Errors are heteroscedastic Joint Test

\begin{tabular}{ccc}
\hline Chi square & Degree of freedom & Probability \\
$\mathbf{1 0 0 . 1 7 2 9}$ & 80 & 0.0631 \\
\hline
\end{tabular}

Source: Output from EViews 10

Besides, we have also calculated the Jarque-Bera statistic of normality. The $H_{0}$ states that the residuals are normally distributed and the $H_{l}$ is its converse. The findings in Table 9 report that the computed p-value for each endogenous variable

${ }^{9} \operatorname{Var}\left(U_{i}\right)=\delta^{2}$ 
is higher than the 0.05 significance level with $2 d f$, showing that we accept our null hypothesis of normality of the residuals ${ }^{10}$. In other words, the results of the JarqueBera statistic show that jointly errors in the VAR (1) system is normally distributed.

Table 9: Results of VAR Residual Normality Tests

\begin{tabular}{cccc}
\hline Component & J-B & df & Probability \\
\hline $\mathbf{1}$ & 4.036781 & 2 & 0.1329 \\
$\mathbf{2}$ & 1.029820 & 2 & 0.5976 \\
$\mathbf{3}$ & 3.220568 & 2 & 0.1998 \\
$\mathbf{4}$ & 1.338011 & 2 & 0.5122 \\
Joint & 9.625181 & 8 & 0.2923 \\
\hline
\end{tabular}

Source: Output from EViews 10

\subsection{Granger Causality Test Results}

In the current study, we have calculated the Granger causality test for different possible pairs of endogenous variables included in the VAR (1) model. The findings in Table 10 report that at the 95\% level of significance, the possible cases for which we reject the $\mathrm{H}_{0}$ include ' $D L E X$ doesn't Granger cause $D L G D P$ ' and ' $D L E X$ doesn't Granger Cause $D C P I$ ', concluding that ' $D L G D P$ does Granger cause $D L E X$ ' and ' $D C P I$ does Granger cause $D L E X$ '. These results demonstrate that there was a unidirectional causality running in one direction; however, no causal relationship was found between the pair of endogenous variables $D C P I$ and $D L G D P$. On the contrary, the null hypothesis in all the remaining cases cannot be

Table 10: Pairwise Granger Causality results (Lags = 01)

\begin{tabular}{|c|c|c|c|}
\hline $\mathbf{H}_{\mathbf{0}}$ & Observations & $F$-stat & $P$-value \\
\hline DLGDP $\neq$ =DUN & \multirow[t]{2}{*}{37} & 1.04283 & 0.3144 \\
\hline DUN $\neq$ DLGDP & & 0.23399 & 0.6317 \\
\hline DLEX $\neq$ DUN & \multirow{2}{*}{37} & 3.02640 & 0.0910 \\
\hline DUN $\neq$ DLEX & & 0.12044 & 0.7307 \\
\hline DINF $\neq$ DUN & \multirow{2}{*}{37} & 0.23338 & 0.6321 \\
\hline DUN $\neq$ DINF & & 0.00064 & 0.9800 \\
\hline DLEX $\neq$ DLGDP & \multirow{2}{*}{37} & 9.53740 & 0.0040 \\
\hline DLGDP $\neq$ DLEX & & 1.08246 & 0.3055 \\
\hline DINF $\neq$ DLGDP & \multirow{2}{*}{37} & 7.22413 & 0.0111 \\
\hline DLGDP $\neq$ DINF & & 8.30952 & 0.0068 \\
\hline DINF $\neq$ DLEX & \multirow{2}{*}{37} & 2.74147 & 0.1070 \\
\hline DLEX $\neq$ DINF & & 4.96669 & 0.0326 \\
\hline
\end{tabular}

Note: The symbol ' $\neq$ ' stands for 'does not Granger cause'.

Source: Output from EViews 10

${ }^{10}$ The skewness and kurtosis calculated values for all components also support the stated finding. 
rejected at the $95 \%$ level of significance, concluding that there is bidirectional causality between different pairs of endogenous variables in the given system.

\subsection{Result of Impulse Responses}

The impulse response traces the dynamic effects of structural shocks on the endogenous variables employed in the estimated VAR(1) model, where each response comprises the effect of a particular shock on one of the endogenous variables of the $\operatorname{VAR}(1)$ system at different time periods, say $t, t+1, t+2, \ldots, T$. In order to visually inspect the dynamic effects of all the endogenous variables on unemployment, we have applied the impulse response function analysis, which indicates the dynamic effects of the different shocks, e.g., real GDP, exchange rate, and inflation rate. The findings of impulse responses displayed in Figure 4 can be interpreted as: (1) A one SD innovation to UNEMP initially has a negative influence on $\ln R G D P$ in the period $1-3$. In period 3, the response of $\ln R G D P$ to $U N E M P$ hits the steady-state level and beyond the $3^{\text {rd }}$ period, the response gradually rises until the $7^{\text {th }}$ period where it achieves the maximum point of the curve (slope $=0$ ), and similarly, beyond the $7^{\text {th }}$ period, the curve again gradually starts a decline towards the steady-state line. The response of $\ln R G D P$ to $U N E M P$ indicates that shocks to $U N E M P$ will have a completely negative influence on $\ln R G D P$ in the short run; however, after some periods, this trend changes to positive, but still, we can say that the whole impact is negative in the short plus long-term, and this finding supports Okun's law (1962). (2) A one SD impulse to UNEMP initially decreases $\ln E X$ up to 2 periods, and this response then sharply declines and hits the zero-line value in the period 2-3 from where it remains in the negative region during the period 3-12, albeit with an increasing tendency. This means that innovations to $U N E M P$ will have asymmetric impacts on $\ln E X$ in the short as well as long-run and such findings validate the outcomes of (Arshad and Ali, 2016; Bakhshi and Ebrahimi, 2016). (3) A one SD innovation of INF to UNEMP initially hits the steady-state value in the $1^{\text {st }}$ period, and then sharply declines up to the $3^{\text {rd }}$ period and remains in the negative region up to the $8^{\text {th }}$ period where it again hits the steadystate level, and after that, it remains in the positive region but moves towards the zero line over periods. The slope of the curve indicates that shocks to UNEMP will have asymmetric impacts on INF both short and long-term; however, we can say that this finding confirms the Phillips curve trade-off relationship and also confirms the findings of Tanha (2018). 
Fig 4: Response to Cholesky One S.D. (d.f. adjusted) Innovations \pm 2 S.E. (Source: Results extracted from EViews 10)

Response of UN to UN

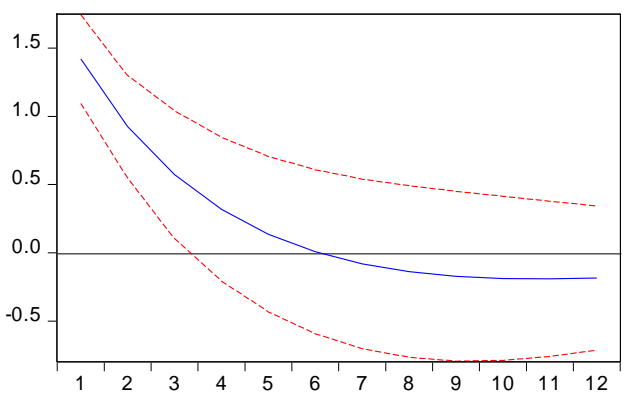

Response of LEX to UN

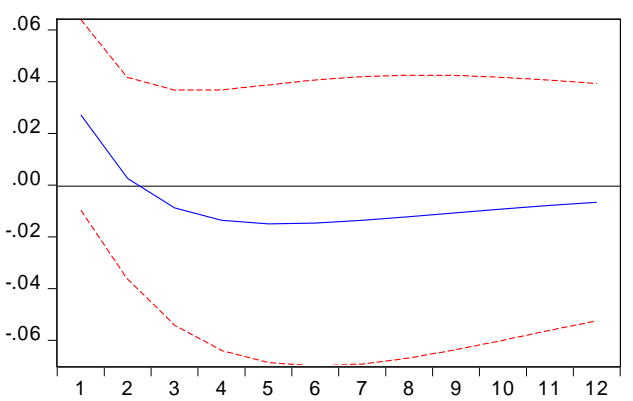

Response of LGDP to UN

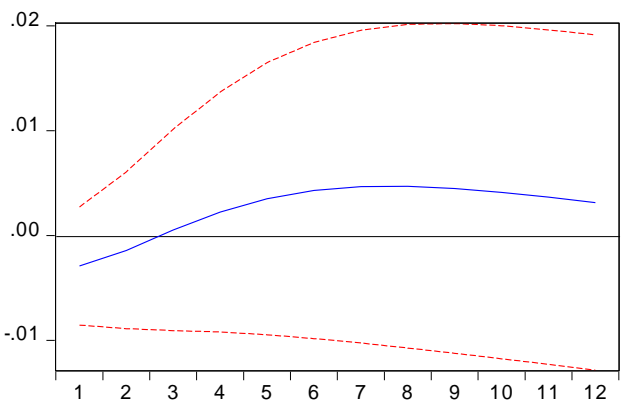

Response of CPI to UN

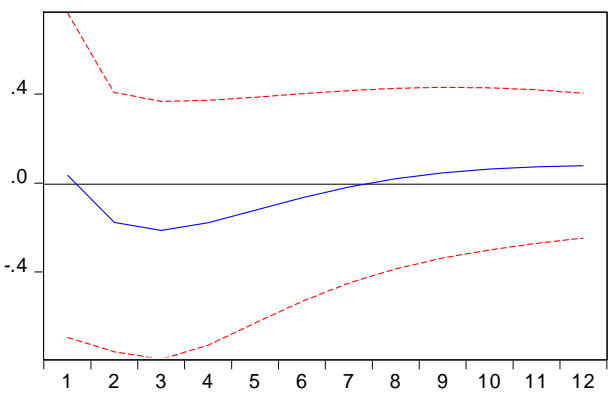

\subsection{Results of Variance Decomposition Analysis}

This analysis presents information on the structural dynamics of the fitted VAR system and how each endogenous variable responds to identified shocks in the remaining endogenous variables in system equations. It is the most popular tool for interpreting the proposed VAR(1) model and it separates the overall change that occurred in an endogenous variable into the contributions explained by the component shocks in VAR models. The results of variance decompositions in Table 11 show that, in the short-run, 100 percent of the forecast error variance decomposition in unemployment is explained by the variable itself, meaning that other endogenous variables have a strong exogenous impact on unemployment. However, in the long-run, $38.19 \%$ of the forecast error variance is characterized by, and the influence of real GDP on unemployment is gradually rising from $1 \%$ to $6 \%$ over years. Besides, the influence of inflation on unemployment in South Africa is very significant, and its influence increases from $5 \%$ to $26 \%$ over periods. Comparatively, the influence of the exchange rate on unemployment is also significant because its impact increases from $2.86 \%$ to $28 \%$ as we move towards the long run. In the case of the inflation rate, this endogenous variable strongly 
predicts itself from the short to the long-term; however, the prediction remains almost the same as time passes. On the other side, unemployment is not a strong predictor of inflation because the future prediction is not excessively strong across the predicted periods.

Table 11: Variance Decomposition using Cholesky (d.f. adjusted) Factors

\begin{tabular}{|c|c|c|c|c|c|}
\hline \multicolumn{6}{|c|}{$\begin{array}{c}\text { Variance Decomposition of Unemployment } \\
\end{array}$} \\
\hline$T$ & Standard Error & UNEMP & $L G D P$ & $L E X$ & CPI \\
\hline 1 & 1.419611 & 100.0000 & 0.000000 & 0.000000 & 0.000000 \\
\hline 2 & 1.774360 & 91.16733 & 0.807687 & 2.861922 & 5.163061 \\
\hline 3 & 2.043273 & 76.61546 & 2.335697 & 8.562880 & 12.48596 \\
\hline 4 & 2.298355 & 62.48624 & 3.962068 & 14.93939 & 18.61230 \\
\hline 5 & 2.540607 & 51.42916 & 5.314354 & 20.54064 & 22.71585 \\
\hline 6 & 2.760390 & 43.56640 & 6.307741 & 24.93684 & 25.18902 \\
\hline 7 & 2.950907 & 38.19694 & 6.987347 & 28.20930 & 26.60642 \\
\hline \multicolumn{6}{|c|}{ Variance Decomposition of Real GDP } \\
\hline Period & Standard Error & UNEMP & $L G D P$ & $L E X$ & CPI \\
\hline 1 & 0.017482 & 2.786317 & 97.21368 & 0.000000 & 0.000000 \\
\hline 2 & 0.027247 & 1.419393 & 87.39433 & 3.155631 & 8.030649 \\
\hline 3 & 0.036033 & 0.832723 & 78.00143 & 5.554411 & 15.61143 \\
\hline 4 & 0.043805 & 0.825012 & 70.88406 & 6.627363 & 21.66356 \\
\hline 5 & 0.050630 & 1.096430 & 65.33692 & 6.767818 & 26.79883 \\
\hline 6 & 0.056651 & 1.449040 & 60.73755 & 6.367453 & 31.44596 \\
\hline 7 & 0.062031 & 1.772526 & 56.71336 & 5.718528 & 35.79558 \\
\hline \multicolumn{6}{|c|}{ Variance Decomposition of Exchange Rate } \\
\hline Period & Standard Error & UNEMP & $L G D P$ & $L E X$ & CPI \\
\hline 1 & 0.115048 & 5.570880 & 4.371525 & 90.05759 & 0.000000 \\
\hline 2 & 0.153413 & 3.160596 & 3.536292 & 84.21660 & 9.086508 \\
\hline 3 & 0.183602 & 2.438448 & 2.779933 & 75.65376 & 19.12786 \\
\hline 4 & 0.208406 & 2.317606 & 2.237274 & 68.56267 & 26.88245 \\
\hline 5 & 0.228689 & 2.354232 & 1.868601 & 63.24272 & 32.53444 \\
\hline 6 & 0.245292 & 2.406235 & 1.624764 & 59.25002 & 36.71898 \\
\hline 7 & 0.258999 & 2.435666 & 1.471103 & 56.16933 & 39.92390 \\
\hline \multicolumn{6}{|c|}{ Variance Decomposition of Inflation Rate } \\
\hline Period & Standard Error & UNEMP & $L G D P$ & $L E X$ & CPI \\
\hline 1 & 2.251293 & 0.026292 & 3.546488 & 14.14590 & 82.28132 \\
\hline 2 & 2.594903 & 0.480998 & 3.315863 & 12.52485 & 83.67828 \\
\hline 3 & 2.731108 & 1.040963 & 3.064938 & 11.34722 & 84.54688 \\
\hline 4 & 2.812416 & 1.383960 & 2.892139 & 10.91676 & 84.80714 \\
\hline 5 & 2.877427 & 1.502247 & 2.812243 & 11.14479 & 84.54072 \\
\hline 6 & 2.936576 & 1.492255 & 2.800048 & 11.79794 & 83.90975 \\
\hline 7 & 2.991807 & 1.441082 & 2.823028 & 12.64921 & 83.08668 \\
\hline
\end{tabular}

Source: Output from EViews 10

Cholesky Ordering: UNEMP LGDP LEX CPI

\section{Conclusion and Policy Recommendations}

This article investigates the economic relationship among various macroeconomic variables, including unemployment, economic growth, exchange rate, and inflation rate for the economy of South Africa by applying the annual data from 1980 to 2018 . The VAR(1) model was employed to explore the dynamic 
relationship between the endogenous variables under consideration, and other relevant econometric approaches and tests have also been used for confirming the validity of the relationship among the estimated endogenous variables. The ADF test reports that the variables are $I(1)$; hence, the Johansen methodology was suggested to explore the long-term association between the variables. No evidence of co-integration was established among the examined variables in the long-run; hence, we estimated the standard VAR model by selecting one lag through checking various lag length selection criteria. All the diagnostic checks of the fitted VAR (1) model support the evidence that the selected model doesn't suffer from any serious issues and the VAR system as a whole is stable.

The findings of the pair-wise Granger causality establish clear evidence of bidirectional causality from economic growth to unemployment, the exchange rate to unemployment, and inflation to unemployment in South Africa at the 5\% significance level. Such significant results imply that one macroeconomic indicator causes another macroeconomic indicator in a dual way, which validates the feedback hypothesis. Furthermore, the Granger causality results demonstrate the presence of unidirectional causality from real GDP to exchange rate and from inflation to exchange rate. The findings report that a rise in inflation would deteriorate the domestic currency of South Africa against the USD; consequently, the economic growth occurred only in terms of accounting. However, no causal relationship between inflation and real GDP has been confirmed in either direction, confirming the neutrality hypothesis. The result highlights that any substantial change in the real GDP of South Africa will not have a substantial influence on the inflationary trend. Furthermore, impulse responses confirm that there is a negative association found between exchange rate and unemployment in the long-run; however, an asymmetric relationship found between employment and inflation over periods. Also, the dynamic association between real GDP-unemployment validates Okun's law. Likewise, impulse responses confirm the evidence that the influence of one factor on the other factor in the system is quite significant and they strongly predict each other in future times.

The findings of this empirical study make a significant contribution to macroeconomics and provide a better understanding to policymakers to attain the higher economic growth targets set by the government of South Africa. The South African unemployment statistics reveal that youth in particular are facing an employment disadvantage because of inadequate education as well as recruiting systems. Therefore, the young population of this economy is lacking problemsolving skills, business awareness, technological know-how, and proper communication skills in order to get a proper job in the marketplace. For ensuring 
more youth employment, the government of South Africa should provide incentives to entrepreneurs to reform human resource practices, skills provision to its youth through training, e.g. job-readiness skills, and party funders should provide various grants to such training programs. Besides, the government of South Africa should provide demand-driven training programs to the youth and must encourage the hiring of valuable staff into jobs. Moreover, the government should enable an environment for small businesses by providing various kinds of incentives and the provision of loans to its youth without charging any interest rates. Such strategies will enable the youth population to open small businesses near the local markets and will easily earn money. Finally, the government of South Africa should devise sound macroeconomic policies and ascertain improvements in the functioning system of its governance for achieving high economic growth in conjunction with job creation in the labor market. Therefore, the South African government should create a supportive environment and flexible labor market policies that attract small businesses and private sector investment which ultimately strengthen the entrepreneurial activity with new entrepreneurial actors in order to create job opportunities and absorb a large pool of unemployed youth. 


\section{References}

Al-Habees, M. A., \& Rumman, M. A. (2012). The relationship between unemployment and economic growth in Jordan and some Arab countries. World Applied Sciences Journal, 18(6), 762-769.

Arshad, S., \& Ali, A. (2016). Trade-off between inflation, interest and unemployment rate of Pakistan: Revisited. MPRA Paper, 78101, Available at: https://mpra.ub.uni-muenchen.de/78101/.

Asteriou, D., \& Hall, S. G. (2007). Applied Econometrics: A Modern Approach Using Eviews and Microfit (Revised Edition). Palgrave Macmillan: New York.

Aurangzeb., \& Asif, K. (2013). Factors effecting unemployment: A cross country analysis. International Journal of Academic Research in Business and Social Sciences, 3(1), 219-230.

Bakhshi, Z., \& Ebrahimi, M. (2016). The effect of real exchange rate on unemployment. Marketing and Branding Research, 3, 4-13.

Chang, S. C. (2011). The interrelationship between exchange rate uncertainty and unemployment for South Korea and Taiwan: Evidence from a Vector Autoregressive Approach. International Economics, 125, 65-82.

Chowdhury, M. S. R., \& Hossain, M. T. (2014). Determinants of unemployment in Bangladesh: A case study. Developing Countries Studies, 4(3), 16-20.

Chuttoo, U. D. (2020). Effect of economic growth on unemployment and validity of Okun's Law in mauritius. Global Journal of Emerging Market Economies, 12(2), 231-250.

Dayioğlu, T., \& Aydın, Y. (2020). Relationship between economic growth, unemployment, inflation and current account balance: Theory and case of Turkey. Open access peer-reviewed chapter, Available at: doi:10.5772/intechopen.93833.

De Grauwe, P. (1988). Exchange rate variability and the slowdown in growth of international trade. International Monetary Fund, Staff Papers, 35(1), 6384.

Dickey, D. A., \& Fuller, W. A. (1981). Likelihood ratio statistics for autoregressive time series with a unit root. Econometrica, 1057-1072. 
Ellen, K. A., \& Abeti, W. (2019). The impact of unemployment on economic growth in China. MPRA Paper, 96100, University Library of Munich, Germany, Available at: https://mpra.ub.uni-muenchen.de/96100/

Engle, R. F., \& Granger, C. W. J. (1987). Cointegration and error correction: representation, estimation, and testing. Econometrica, 55, 251-276.

Frenkel, R., \& Ros, J. (2006). Unemployment and the real exchange rate in Latin America. World Development, 34(4), 631-646.

Granger, C. W. J. (1969). Investigating causal relations by econometric models and cross spectral methods. Econometrica, 35, 428-438.

Hossain, E., Ghosh, B. C., \& Islam, K. (2012). Inflation and economic growth in Bangladesh. Journal of Arts, Science and Commerce, 3(4), 85-92.

International Labour Organization. (2019). Statistics and Databases, ILOSTAT Indicators. Switzerland, Available at: https://www.ilo.org.

Islam, M. S., \& Sahajalal, M. (2019). An empirical study of GDP, exchange rate, inflation and unemployment in Bangladesh. International Journal of Multidisciplinary Research and Development, 6(6), 51-53.

Johansen, S., \& Juselius, K. (1990). The maximum likelihood estimation and inference on cointegration-with application to demand for money. Oxford Bulletin of Economics and Statistics, 52, 169-210.

Kaur, K. (2014). An empirical study of inflation, unemployment, exchange rate, and growth in India. Asian Journal of Multidisciplinary Studies, 2(10), 1921.

Khalid, W. (2017). Effects of interest rate and exchange rate on the stock market performance of Pakistan: A cointegration approach. Journal of Finance and Economics, 5(5), 219-232.

Khalid, W., \& Khan, S. (2017). Effects of macroeconomic variables on the stock market volatility: The Pakistan experience. International Journal of Econometrics and Financial Management, 5(2), 42-59.

Khan, R. E. A., \& Gill, A. R. (2010). Determinants of inflation: A case of Pakistan (1970-2007). Journal of Economics, 1(1), 45-51.

Kingdon, G., \& Knight, J. (2004). Unemployment in South Africa: The nature of the beast. World Development, 32(3), 391-408. 
Levinsohn, J. (2008). Two policies to alleviate unemployment in South Africa. Center for International Development at Harvard University, Working Paper, 166.

Lütkepohl, H. (2005). New Introduction to Multiple Time Series Analysis.: Springer Berlin Heidelberg: Germany.

Mahmood, Y., Bokhari, R., \& Aslam, M. (2013). Tradeoff between inflation, interest and unemployment rate of Pakistan: A cointegration analysis. Pakistan Journal of Commerce and Social Science, 7(3), 482-492.

Makaringe, S. C., \& Khobai, H. (2018). The effect of unemployment on economic growth in South Africa (1994-2016). Working Paper, 2018/05, 1-17.

Maswanganyi, N. (2014). Job creation lags behind SA's economic growth rate. Available at: http://www.bdlive.co.za/national/labour/2014/03/19/jobcreation-lags-behind-saseconomic-growth-rate. Accessed: 2016/09/10.

Mohammadi, T., \& Gholami, A. (2008). An investigation into the effects of the policy of exchange rate unification on major variables of macroeconomics. Economic Questionnaire, 29, 49-74.

Medium Term Budget Policy Statement. (2018). National Treasury Republic of South Africa. Available at www.treasury.gov.za.

Organization for Economic and Cooperation Development. (2019). Main Economic Indicators (MEI). Available at: https://stats.oecd.org.

Okun, A., \& Potential, G. N. P. (1962). Potential GNP and its measurement and significance, American statistical association. Proceedings of the Business and Economics Statistics Section, 98-104.

Osinubi, T. (2005), Macroeconometric analysis of growth, unemployment and poverty in Nigeria. Pakistan Economic and Social Review, 523(2), 249-269.

Phillips, A. W. (1958). The relation between unemployment and the rate of change of money wage rates in the United Kingdom, 18611957. Economica, 25(100), 283-299.

Sanchez, J. M., \& Liborio, C. S. (2012). The relationships among changes in GDP, employment, and unemployment: This time, it's different. Economic Synopses, Available at: https://doi.org/10.20955/es.2012.13

Sims, C. A. (1980). Macroeconomics and reality. Econometrica, 48, 1-48. 
Tanha, R. (2018). Impact of economic growth and inflation on unemployment in Bangladesh: A time series analysis. A Thesis submitted to the School of Business and Economics, United International University, Dhaka, Bangladesh.

Tenzin, U. (2019). The nexus among economic growth, inflation and unemployment in Bhutan. South Asia Economic Journal, 20(1), 94-105.

Thayaparan, A. (2014). Impact of inflation and economic growth on unemployment in Sri Lanka: A study of time series analysis. Global Journal of Management and Business Research: B Economics and Commerce, 13(5), 45-53.

Tunah, H. (2010). The analysis of unemployment in Turkey: Some empirical evidence using cointegration test. European Journal of Social Sciences, 18(1), 18-38.

Vrieze, S. I. (2012). Model selection and psychological theory: A discussion of the differences between the akaike information criterion (AIC) and the bayesian information criterion (BIC). Psychological Methods, 17(2), 222-243.

World Bank. (2019). World Development Indicators Database. Available at: http://www.worldbank.org.

Zivanomoyo, J., \& Mukoka, S. (2015). An empirical analysis of the impact of unemployment on economic growth in Zimbabwe. Archives of Business Research, 3(6), 38-49. 